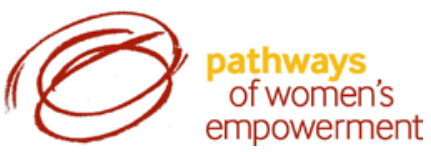

\title{
Researching Empowerment: On Methodological Innovations, Pitfalls and Challenges.
}

\author{
Akosua Darkwah and Dzodzi Tsikata
}

\section{Introduction}

The consensus that empowerment is context specific and processual has provided the possibility of gaining new insights into women's lives in different contexts. Realising this demands methodological innovations, but also the navigation of challenges. Discussions within the West African hub of the RPC before we began research concluded that our contribution to the empowerment literature would be to identify what changes had occurred in women's lives in particular contexts over the years, which of these had been positive and which had been setbacks. We decided therefore to select research instruments which would be up to the task of plotting change within the limits of a five year research programme. We agreed on a) a survey into women's everyday lives focusing on the key thematic areas of the pathways rpc- work, voice and body, and additional indicators such as education, health, access to justice, personal freedoms and significant relationships; and b) life story interviews with three generations of womendaughter, mother and grandmother who lived in close proximity to each other at the time of the research, identified through the survey.

The use of an intergenerational approach in both the survey and in-depth interviews was an innovative way of identifying changes in women's lives which also allowed us to focus on women's everyday lives at different stages in their life cycle. Interviewing the three generations of women in depth was particularly exciting in its possibilities for comparison when discussed in relation to changing national contexts. The survey and life story interviews presented some methodological challenges we would like to discuss in this paper. In the studies, we explored our own assumptions about empowerment and also asked respondents what they understood by the concept of empowerment. The two approaches to researching empowerment were expected to be complementary.

The questions based on our assumptions about empowerment were quite straightforward. On the other hand, the questions about empowerment raised all manner of questions- linguistic complications and possible biases, comparability across the different languages of the study and what meaning and weight to give to philosophical and attitudinal questions as opposed to questions about actual practice. This paper is an account of the study's methodological choices, with special references to their implications for the findings of the study. The paper begins with a brief discussion about the conceptions of empowerment guiding the study and how these influenced the methodological strategies of the study. This is followed by a discussion of the two methods used in the study, the key assumptions of the study, the research questions, sampling procedures and interview processes. The discussion identifies the innovations, particularly the 


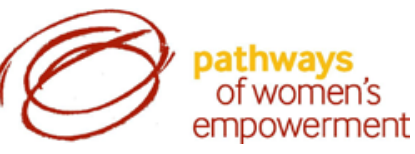

intergenerational approach and its value for generating particular types of findings. As well, the methodological challenges and pitfalls are examined. This is followed by a section which illustrates some of the benefits and pitfalls of the study's methodology. These are a) the challenge of making sense of the potential conflicts in the subjective and objective definitions of empowerment; b) the challenge of analyses presented by the homogeneity of the study sample; c) discovering the changing significance of education; and d) the additionality of capturing the particularities of context. The last segment discusses implications for future studies of empowerment.

\section{Conceptions of empowerment and their implications for research methods}

Some of the elements of the conceptions of empowerment influenced the choice of research methods. There was consensus around some of these elements while others continued to be the subject of debate. For example, there was agreement within the group that empowerment was a non-linear process in the nature of a continuum. There was also agreement that empowerment was not in the nature of a destination. Thus a person empowered today might be disempowered tomorrow by changes in their circumstances. Another agreement was that there were different elements/dimensions of empowerment. Thus a person could be economically empowered but could have some social disempowerment and vice versa. At the same time, we assumed that one aspect of empowerment could help to empower a person in other respects. These agreements notwithstanding, there were unresolved questions about whether it would be possible to find that some people were more empowered than others, or whether comparisons were only possible with respect to the same person at different times in their life. Also unresolved was the question of whether each individual had a particular path/trajectory to empowerment or whether some common indications were discernible in the pathways to empowerments.

A second set of issues was related to how to measure objective criteria- as identified by the researchers as both direct and proxy indicators of empowerment; and subjective criteria, as identified by respondents. Thirdly, how to account for the material and non-material dimensions of empowerment and their relationship was considered important. Material dimensions related to work and working conditions, livelihood outcomes and access to resources including property and institutions. Non-material aspects of empowerment included a person's sense of self worth and autonomy, the freedom to make personal decisions of different kinds and the quality of relationships. Empowerment was also seen as change for the better and the enlargement of capabilities and choices. This is related to both the objective and subjective criteria of empowerment. Last but not least was a general agreement that the nature of empowerment and disempowerment are framed by context. These agreed conceptions and debates about empowerment had implications for the selection of research methods and the framing of research questions and the research instruments. 


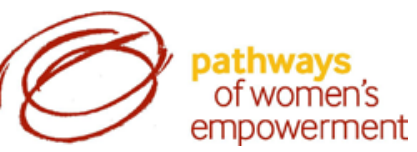

\section{Researching Empowerment: The Survey and In-Depth Interviews}

Ideally, to be able to examine empowerment as both a process and continuum, we would have conducted a longitudinal study. This would have allowed us to track a group of women over time focusing on both the individual and group processes of empowerment. Doing a longitudinal study would have made it possible to identify both individual family circumstances and changing national contexts and the extent to which these two factors constrained or enhanced women's empowerment during different periods in their lifecycle. However, the five year time span during which the pathways project was to be executed did not make this possible. As we were interested in examining the extent to which Ghanaian women have become empowered or disempowered over time and identifying the factors responsible, the innovation we came up with was to combine a survey of three generations of women and life story interviews with three women representing three generations (daughter, mother and grandmother) in a number of families. This compromise allowed us to understand the ways in which a constellation of factors in an individual's life - both family circumstances and local/national context - made it possible for a woman to empower herself.

In both the survey and life story interviews, we used a combination of objective and subjective criteria for measuring empowerment. By objective criteria we refer to the empowerment indicators that we identified prior to our entry into the field. There were four of these indicators - decision making about politics and associations, the ability to participate in civic life without restrictions, social standing and finally control over life processes. We had six measures of control over life processes which were a) egalitarian relationships with significant others; b) sexual and reproductive rights- sex, reproductive decision making, contraception, abortion, reproductive health needs; c) general healthcare needs; d) money and assets; e) choice of work and whether or not to work and finally, f) freedom from violence in relationships. By subjective criteria, we refer to indicators such as whether or not a person felt empowered or disempowered and their definition of empowerment.

Using both objective and subjective measures of empowerment allowed us to examine the extent to which respondents shared our indicators of empowerment. These indicators also enabled us to investigate the extent of enjoyment of citizenship rights by women. The survey was in nine parts, including a section on the socio-demographic characteristics of each respondent. Each section focused on either a dimension of empowerment or the factors that we had assumed shaped the extent to which an individual was empowered or disempowered. Section two focused on household composition, assets and characteristics. In sections three and four we focused on both productive and reproductive labour. In section five, our emphasis was on women's social standing, personal freedoms, decision-making abilities and their experiences of violence. Section six focused on their membership in associations and political participation. In section 


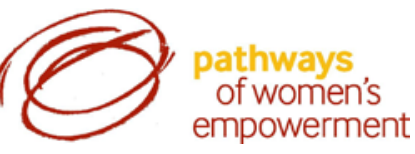

seven, we assessed the extent to which resources provided by the state and various nongovernmental agencies had been important for women. In the final section of the survey, we provided an opportunity for the respondents to provide us with their own understandings of the concept of empowerment in terms of both their definitions of empowerment and the extent to which they defined themselves as empowered women. Our overall intention was to examine the interconnections between the nine parts by cross tabulating different elements such as education and work; work and decision making; education and decision making; work and access to institutions and so on. In addition, the design of the survey enabled us to explore our assumptions about the factors shaping women's empowerment or lack thereof in the Ghanaian context. The following five assumptions guided this survey:

o The higher a woman's level of education, the more indicators of empowerment she is likely to fulfill.

o Women who have conformed to societal norms (married, children, gainful employment) are more likely to perceive of themselves as empowered than women who have not.

o Women with parents, guardians or other adults who promote gender equality are more likely to be empowered as adults.

o Women with empowering work are more likely to experience more indicators of empowerment.

o The more religious women are, the less likely they are to pursue "control over life processes” indicators.

Since it was impossible to use a survey to track the trajectories of particular women in their attainment of an empowered status in various aspects of their life, we also conducted life-story interviews of three generations of women (grandmother, mother and daughter). The life-story interviews were intended to illuminate change processes and nuances and foreground issues such as national context and local specificities, which could not be addressed with survey questions. Using the life story approach allowed us to discuss women's lives in a fairly logical manner from childhood through to their present age. We begun with an understanding of their childhood years and discussed whether their parents, guardians and significant adults in their life had created a sense of difference based on gender through their decisions on education and the nature of household chores assigned to male and female siblings. Next, we discussed the marital lives of the women if they had ever been married. Here, we were interested in questions of autonomy so far as decision making in terms of choosing a marital partner and within the marital home was concerned. We also discussed the possible impacts of marriage and childbearing on their working lives. In discussing their working lives, we were not only interested in the kinds of jobs they had and why they chose those jobs but also the ways in which family and particularly work colleagues supported or did not support them with their work. We also explored their associational life and the importance they attached to these activities. In the final sections of the 


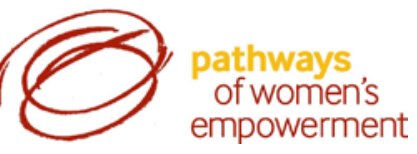

interview, we asked the women a series of questions to elicit their perceptions about their state of empowerment. This included the ways in which in comparing themselves with the two other women in their family they were different for better or worse; their definitions of empowerment and whether or not they considered herself empowered as well as their reasons for saying so.

To determine who should be interviewed, we were guided by a few considerations. First and perhaps most importantly, we wanted to be able to capture the diversity of Ghana so as to be able to best ascertain the extent to which local context shaped the attainment of empowerment at different points in a woman's life. Ghana has three major ecological zones - the northern savanna, the middle forest belt and the coastal belt which shape economic activities such as farming, fishing and extractive activities. The coastal belt also includes two of the three largest cities in the country where formal sector employment is highest. Location thus shaped the kinds of jobs available to women and we were interested in assessing how that influenced their choices and affected their experiences of empowerment. We thus chose to work in three of the ten regions of Ghana which would represent the three ecological zones (the Northern, Ashanti and Greater Accra Regions. The three regions also provided variations in systems of kinship and inheritance (matrilineal and patrilineal), religion (Christian, muslim and traditional religion) and the incidence of poverty. We were also interested in the ways in which rural locations with its more limited access to good educational institutions and formal sector jobs shaped women's choices and strategies. Thus, in each of the three regions, we worked in one urban site and two rural sites in recognition of the fact that the majority of Ghanaians live in rural areas. In each of the urban sites, we interviewed women in two different sites representing different income groups. In summary then, we interviewed in twelve communities located in three urban and six rural areas across three regions of the country.

In terms of the sample size, we interviewed six hundred women; two hundred in each of the three regions (eighty in the urban areas and one hundred and twenty in rural areas in each of the three regions). Respondents were from three age categories: 18-29; 30-49; 50 and above. Our lower limit of 18 was determined by the legal definition of adulthood in Ghana while the upper limit was in recognition of the life expectancy rate of 59 for Ghanaian women. Also, the number of women sampled in each of these three age groups was in keeping with the fact that the Ghana as a developing country has a relatively young population. Thus, the 18-29 year olds constituted $40.3 \%$ of the sample, the $30-49$ year olds constituted $39.5 \%$ of the sample while those over 50 constituted $20.2 \%$ of the sample. A total of twelve sets of intergenerational life-story interviews, one each from the twelve communities in which we worked were conducted. Two main considerations determined which families were interviewed in each community. First, the three generations had to exist, which was quite difficult as evident in the fact that we had less than fifty families to choose from the six hundred women we interviewed. In some cases, women had only sons or grandsons. In the cases where daughters/granddaughters existed, some were younger than 18. In yet other cases, grandmothers or in a few cases, mothers had died. Beside the fact that the three generations were alive and of the right gender/age, the most crucial 


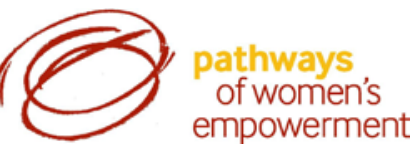

determinant was whether or not the three generations lived in the same community or close enough (within a half hour's drive) so that they could be interviewed conveniently.

\section{Methodological challenges}

The first challenge we faced was linguistic- what would be the words or phrases for empowerment, empowering, and empowered woman in the five languages of our studyDagbani, Gonja, Asante Twi, Ga and Dangbe? We turned to our fifteen survey personnel to help us identify the words. We decided to ask them rather than linguistic experts because we wanted to find everyday terms rather than usage which might be more linguistically accurate, but which would not be commonly used. After much discussion and laughter, they came up with "man kpansibu” (dagbani), "ki elento” (gonja),” obi a odeneho” (twi), "moko ni hie ehe” (ga and ga adangbe) to denote the phrase for "a person who is empowered". These words denoted strength and autonomy/independence. This raised a number of questions. Were the words and phrases comparative across the five languages? Related to this, would these words not carry within them biases about what we were trying to uncover in the field? Would we learn something new about what was important to women and how they saw empowerment?

Regarding the linguistic, the question which came often when the word kpansibu or elento was used- what kind? It meant that there were different kinds of strengtheconomic, physical and they wanted us to specify what we were interested in. Related to this was the overwhelming economic/financial slant respondents gave to the question of empowerment across the board. Did this have to do with the words. or was the economic overwhelming in the lives of respondents? A conversation with a friend with a long tradition of political activism who speaks Gonja was revealing in this regard. His term for empowerment in Gonja was "abol” which translates literally as voice. "Abol” when used in relation to other words could mean having a sweet voice and liking sweet things. It became clear to us that the respondents, under our influence had focused on a particular dimension of empowerment which did not stress voice.

Related to the linguistic issue was the subject matter bias of the study of everyday lives. The focus on issues such as education, work, assets, marriage and family life and associational life, did predispose respondents to focus on the material dimensions of empowerment. On the other hand there were questions about political participation, justice seeking behaviour and autonomy and decision-making in relationships with significant others which did not gain as much traction among respondents in the sense that the majority of respondents had not experienced more than the most basic indicators 


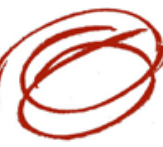

pathways

of women's

empowerment

of empowerment. What should this tell us- that women in their everyday lives were more concerned about the material, or that they found it easier to discuss such matters?

Respondents did not have a uniform attitude to questions which ask them to reflect on their lives and on philosophical questions. There was much amusement and exasperation, but also flashes of deep insight. As well, there were many contradictions and particularities which were significant in pointing to the difficulties of making policy on the basis of personal notions of empowerment. Some of these are discussed more fully in the paper on research findings. There are some findings which show differences among the three generations. This could be attributed either to changing contexts, to changing life cycle situations, or to both. It therefore requires that care be taken in interpreting findings. In the next section, some findings are discussed to illustrate the value of some of the methodological innovations and their challenges.

\section{Some Findings and their Implications}

5.1. Uncovering the contradictions between the subjective and objective definitions of empowerment.

There were four senses in which respondents used the term empowerment in the life story interviews. These were: empowerment as empowering others; empowerment as independence/control over life; empowerment as capacity to take care of self/family; and empowerment as consciousness. Some of the definitions are offered below.

a. Empowerment as empowering others

- An empowered woman is involved in getting people to build up her society and community. She encourages others while a disempowered woman does not motivate others- Addokope daughter

- An empowered woman is one who can help herself and others, who has a job, knows about herself and her environment and her community. "You cannot stay in the house and be empowered. If you join societies, organisations, communities and other social things, even spiritually you will be empowered. If you are enlightened, empowerment will follow.” - Damongo mother

b. Empowerment as independence/control over life 


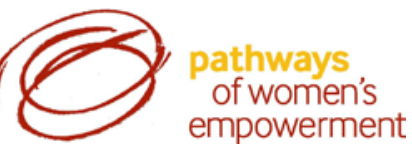

- An empowered woman is one who has her own work, can get whatever she wants, nobody does anything for her while a disempowered woman does not work and so depends on others- Korle Gonno mother

- An empowered woman is a woman who is hardworking and can do things for herself. A disempowered woman is a woman who does not have money and cannot do things for herself - Tortimekope grandmother

c. Empowerment as capacity to take care of self/family

- One who has education so that if a man won't give her money, she can provide for herself - Atonsu daughter

- An empowered woman is one who has her money, property and has no worries while a disempowered woman is one who is poor and always thinking about what to eat Behenase aunt

- Is one who is well educated, has work and is married to a rich man. A disempowered woman has no education and no work - Ahinsan grandmother

- An empowered woman can carry every burden of her children; their hospital bills, what they wear even if their father does not know anything about it. A disempowered woman will be worried about how she will take care of her children - Tortimekope mother

- One who can distinguish herself and prove her worth in whatever she is doing in her economic life. When you can do what is expected of you, then you are empowered. Gumani grandmother

\section{d. Empowerment as consciousness}

- An empowered woman is one who is educated, knows her rights and is able to enjoy these rights. She did not consider herself empowered because she has not started work and is not married. Most problems comes with marriage and work and that is the time you have to handle these problems and know whether or not you are empowered Damongo daughter 


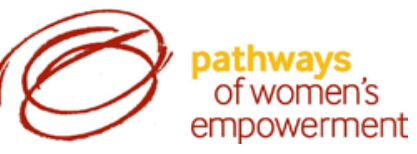

The above definitions resonate with some of the objective dimensions of empowerment. Some form of activism as a dimension of empowerment is offered by a few of the definitions. The definitions highlight the role of work as a resource. However, they qualify the kind of work in terms of it being well-paid or what it contributes to livelihood outcomes. Thus the stress is more on the instrumental as opposed to the instrinsic value of work. Matched against the study's indicators for empowering work ${ }^{1}$, there was general agreement between the objective and subjective indicators about the importance of having work which could deliver livelihood outcomes which allow a person to look after themselves and their family and acquire property. However, many of the $70 \%$ of the women who were earning below the minimum wage considered themselves empowered on account of having work which allowed them to maintain their families or assist their husbands. Secondly, their notions of empowerment went beyond the material and affirmed the study's combination of the material and non-material dimensions of empowerment.

\subsection{The Challenge of a Homogeneous Sample}

Our findings illustrate both the challenges and rewards of using an intergenerational approach in the study of empowerment. One such challenge was that as it privileged respondents on grounds of age, it did not deliver variations in our respondents which would have strengthened the comparative aspects of the study. We had assumed that there would be enough variance between the three age groups to enable us discuss interconnections among a number of variables. We discovered, however, that while on a few variables such as education, there was some differences among the three groups, on the majority of indicators, there was little difference among them. For example, political participation measured as exercising the right to vote is very high among the two older groups of women. The only exception was the youngest group of women. This had to do primarily with the fact that at the time of the last election four years prior to the conduct of the interviews, a fair number of the women were not eligible to vote. Similarly, we found that

\footnotetext{
${ }^{1}$ An example of the study's objective criteria were the indicators for empowering work used for the survey. For those in salaried employment we adopted the key elements of decent work as identified by the ILO. These included fixed hours of work, periods of break, maternity leave and regular monthly wages among other things. As workers in the informal economy who were in the majority were not guaranteed these benefits, two indicators- whether they had registered their businesses and if they had employees were selected to explore their working conditions. Registration provides several benefits to a business, including ease of relations with public institutions and some protection from state harassment, while having employees implies a certain scale of business. For both salaried and self employed workers, additional indicators were wage levels above the minimum wage, access to loans, having savings and assets.
} 


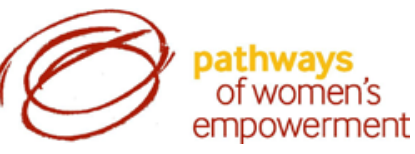

for all three groups of women, associational life consisted mainly of involvement in Christian associations. A third example of homogeneity across the three groups is also reflected in the kinds of economic activities in which these women are engaged. The majority of the women (76\%) were self-employed in small-scale enterprises. Only a fifth of these women had employees.

Even in the cases where there was some amount of heterogeneity, closer inspection of the data highlighted many points of similarity across the three groups. A good example of this is the extent to which these women had differences in educational levels. On the one hand, in comparing the numbers of women aged above 50 who had never been to school with the numbers of women aged between 18 and 29 who had been to school, one could clearly see a difference between the two groups. Only 30.6\% of the women aged above 50 had been to school compared with $76.5 \%$ of those aged between 18 and 29. Clearly, the fact that more than twice as many women aged 18-29 had been to school compared to those above 50 is a significant difference that needs to be acknowledged. This difference persists for primary and secondary school as well. However, in terms of post-secondary education, there is not much of a difference between the youngest and oldest group of women. In both groups, $4.1 \%$ of the women have some form of tertiary education, be it a university degree or a certificate of some sort. Considering that access to the higher levels of the occupational hierarchy in the formal sector is largely determined by one's educational levels, particularly the attainment of tertiary education, what these numbers tell us is simply that while a lot more women are being provided with an education than was the case a generation ago, the impact of such change has been negligible. Thus, while we indeed have three times as many women working in the formal sector among the group aged 18-29 as compared to those aged above 50, the majority of them work as lower level employees. This overwhelming homogeneity made it difficult to compare the three groups of women as we had initially imagined. Often, there just was not enough statistically significant variability to make much of a case about the ways in which older women were more empowered or vice versa.

\subsection{Discovering the Changing Significance of Education}

Having said this, it is also important to point out that the intergenerational triangulation approach where we combined our survey data with our life-story interviews had its advantages. Key among these was the ways in which we were able to illuminate the nuanced processes by which women came to acquire particular indicators of empowerment or otherwise. As earlier mentioned, we measured our fourth indicator of empowerment, control over life processes, in a variety of ways which included money and assets that women had and the choice of work open to them. One of our key assumptions had been that a highly educated woman would fulfill more indicators of empowerment than a poorly educated woman. Our findings suggest that while this 


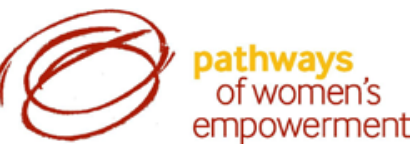

could very well be true for women aged 30 and above, it was less so for the youngest women in our study, so far as choice of work is concerned. Although women's access to formal education had improved over the years, our intergenerational life-story interviews showed very clearly how access to formal sector employment was not readily available for young women with high levels of formal education as it had been for the middle aged women in our study. The mother and daughter we interviewed had similar levels of training in secretaryship. Indeed, the daughter had started her job search with the qualifications her mother had acquired over her lifetime. However, she had already spent a couple of years searching unsuccessfully for a job. The mother in this story had grown up in the early post independence period when the value of education had been emphasized thanks to modernization theory. An Education Act had been passed in 1961 to ensure fee free education for all children of school going age. As a tool for social mobility, education had no parallel in the early post independence period and the mothers' generation had especially benefited from this. Many had been able to make an almost effortless class transition with the benefit of secondary education. Although few (less than 6\%) of the mothers in the sample had had university education, several of them could affirm that education had changed their lives profoundly, when compared with their mothers- the grandmothers. The daughters as exemplified in the case here were another matter altogether. Circumstances beyond her control had conspired to make her job search difficult. Key among this was the fact that Ghana embarked on a structural adjustment program in the 1980s which resulted in the shrinking of the formal economy in general and the public sector jobs in particular (Tsikata, 2008). Fewer job opportunities in the public sector combined with the larger pool of women with educational qualifications means then that the daughter finds herself searching for a job in an economy with few available openings and many potential employees as compared to her mother who started her working life in a period where the job openings were more plentiful and the qualified applicants fewer. Several of the daughters we interviewed had not gone much further than their mothers in terms of their educational qualifications. Those who had, such as the daughter in question here were worried about their job prospects. In these days of graduate unemployment, they should be worried.

What does this say about the status of education in women's empowerment? In arguments with colleagues in the RPC, we had argued that because women in Africa had always worked and earned incomes, education which would allow them entry into decent work would have a more profound impact on their lives than the freedom and the ability to work per se. In the light of what is emerging how might one view this argument about education? The qualification about the quality of work is still valid. However, education is not guaranteed to deliver empowerment in the way in which we had considered it. This changing significance of education at least in the Ghanaian context is one that would have been difficult for us to assess had it not been for our innovative use of intergenerational life-story interviews. 


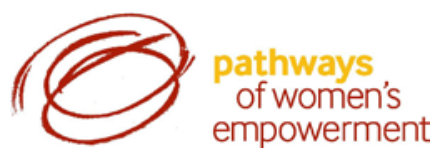

\subsection{Capturing the Particularities of Context}

As indicated in our paper discussing our findings, one element of the context of women's empowerment relates to the present conjuncture of liberal democratic politics, economic liberalisation and the rise of conservative social forces. This conjuncture in Ghana was preceded from the late 1970s to the mid 1980s by political and economic turmoil. One social group which suffered livelihood stresses and economic setbacks in this period was market women. Between 1979 and the mid 80s, there were episodes of market demolitions, floggings, prosecutions, price fixing and edicts banning women from selling non perishable goods (See Robertson, 1983; Tsikata 1997; Darkwah, 2006 for fuller accounts of these events). While economic liberalization brought an end to these episodes, hawkers have continued to experience regular episodes of forced removals and harassment. In the life story interviews, one or two women had recalled that period which they identified as the reason why they had shifted from one livelihood activity to another or relocated from an urban area to a rural area. One respondent who had not quite experienced this period argued that although she thought that life was harder now than it used to be in her mother's time when it had been easier for them to find work and look after themselves, she thought that women were more empowered now than they used to be because in the Rawlings era, they could not openly buy cloth because of political repression. These days, anyone with money can buy cloth (Abodom, daughter). This reference to context was expected and confirmed what researchers already knew from the literature. However, there were some more unexpected findings which uncovered the significance of certain contextual conditions, something which would not have been possible but for the life stories. Two of these- the role of the Catholic church as a complicating factor in religion and the problematic impacts of fostering on women's lives- are discussed below.

Both the survey and the life story interviews revealed that the sum of women's associational life across the three generations was their involvement in religious associations. Some grandmothers had been in work based collectives but had given them up on retirement. Church was the constant for young and old and several extolled its advantages- it allowed for self expressionyou could become a leader; you could learn several things including public speaking; you could even take a loan from your church group, they provided financial support in times of sickness and calamity, and if all else failed, they gave you a good burial. This discovery and the finding that for most of the women, their involvement in politics was limited to voting in the district and national elections raised questions about the constraints of religion. At the same time, it pointed to the range of uses to which religious associations could be put, beyond the spiritual. As well, it raised the question about the availability of civic and other organizations in some locations. This was supported by what the life story interviews revealed about the pivotal role of the Catholic Church in the lives of women in Northern Ghana. For one mother, joining the Catholic Church was literally life defining. She came from a Muslim family, but was attracted to the Catholic Church because of its focus on development issues and its ecumenical approach to matters of faith. She started catholic school, converted and became a leader- worked for the church, 


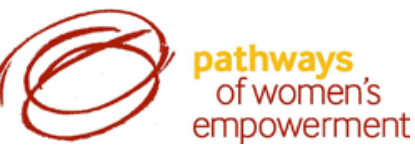

traveled abroad, used the benefits of the workplace to help her community and has become the elected Assembly person of her community. For others, it was not so dramatic- but it conveyed that the church was more than a place for spiritual growth. One of the assumptions we made before starting field-work was that the more religious women were, the less interested they would be in striving for empowerment related to autonomy and control over decisions that affected a person. We still do not know the status of this assumption, but from the 36 life stories, this assumption probably needs to be qualified.

Another interesting finding about the context of empowerment concerned the significance of fostering in shaping the lives of girls. This confirmed the findings of some studies on fostering and domestic labour in Ghana (Apt, 2005; LAWA- Ghana, 2003). Fostering is a customary practice in Ghana where young children are given to family members to raise, train and generally prepare for adulthood (LAWA Ghana, 2003; Tsikata, 2008). In this way, a number of children are sent from rural areas to live with their relations in urban areas. The children perform household tasks for the relative, but they are regarded as kin, and not as employees. Especially for girls, occupational socialisation starts early in life. Children were often given to foster parents who had a better-socio economic standing than their own families, and who had a good reputation in society (Clark, 2002). Traditional fostering was done with the understanding that the children so fostered would contribute to the household chores.

In our life story interviews, some of those women who had no education attributed this to being fostered by family relations who put them to work. The survey would not necessarily have uncovered the extensive experience of fostering across the three generations and geographical locations. In some cases, these persons had no education themselves and trained them in their own occupations. In other cases, their biological children were put in school while the fostered child became their nanny. The Ahinsan mother, who had been fostered by a then childless aunt was put in secondary school, but had had her education truncated on account of teenage pregnancy. She was now trading in recycled plastic containers in several markets. Her younger siblings who were fostered by the same aunt (the Ahinsan grandmother) were not given a similar opportunity, because the aunt considered that they might also get pregnant, thus wasting her resources. However, her own daughter, who was born years later went on to attend university and now lived in Europe and sent remittances to her mother. The life-story cases give contours to what is known about fostering and shows its role in the trajectories of generations of women.

\section{Implications for future studies of empowerment.}

In using the intergenerational survey/lifestory interview approach, we have learned a number of useful lessons. First is the fact that this approach, particularly the intergenerational life-story interview approach offers key insights into understanding empowerment that may very well be lost in using other approaches. The intergenerational life-story interviews illuminated the 


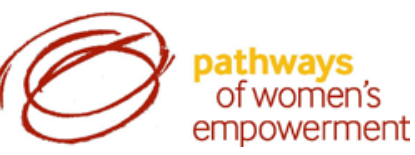

importance of socio-political/socio-economic context in determining the ease with which an individual can use widely understood mechanisms for attaining empowerment to actually do so. The inter-generational survey could very well tell us about the three groups and their various levels of empowerment, but the intergenerational life-story interviews made it possible for us to understand the role of context in explaining these differences. The inter-generational life-story interviews thus make it possible to offer a nuanced understanding of different pathways to women's empowerment. As illustrated in the lives of the family in Northern Ghana, a path that led to empowerment in the 1970s may not lead to empowerment in the twenty-first century.

Second, our unilinear focus on age as the key variable in determining our sample produced a fairly homogenous sample which made it difficult sometimes to cross-tabulate various variables. For us, it was a missed opportunity to study the statistically significant ways in which working contexts shaped a woman's experience of empowerment. On the other hand, we found the use of age as a marker of difference useful in many ways. The key lesson then would be for future studies to sample purposively using two criteria; age and any other variable of interest to the researchers such as educational levels, occupation and so on.

\section{References}

Apt, N. A. (2005). A Study of Child Domestic Work and Fosterage in Northern and Upper East Region of Ghana. UNICEF.

Clark, G. (2002). ‘The Plight of the “Girl Maid”', Sister Watch, 1(14).

Darkwah, A. K. 2002. "Trading goes Global: Ghanaian Market Women in an Era of Globalization.” Asian Women, Vol. 15, pp. 31-47.

LAWA-Ghana (Leadership and Advocacy for Women in Africa-Ghana), (2003). Domestic Workers in Ghana: First to Rise and Last to Sleep. Washington: GULC.

Robertson, C. 1983. “The Death of Makola and Other Tragedies”, Canadian Journal of African Studies, Vol. 17, No. 3, pp. 469-495. 
Pathways of Women's Empowerment: What are we Learning?

Conference 20-24 January 2009

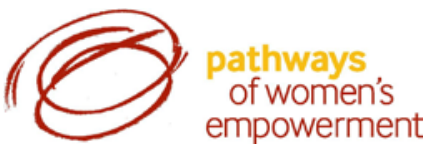

Tsikata, D. 1997. “Gender Equality and the State in Ghana: Some Issues of Policy and Practice.” In A.M. Imam, A. Mama, A. and F. Sow (eds.) Engendering African Social Sciences. CODESRIA Book Series, Dakar.

Tsikata, D. (2008). 'Informalization, the Informal Economy and Urban Women's Livelihoods in Sub-Saharan Africa since the 1990s' in S. Razavi (ed.), The Gendered Impacts of Liberalization: Towards “Embedded Liberalism”?, Routledge \& UNRISD, London and Geneva. 